\title{
Hydrothermal Reduction of $\mathrm{NaHCO}_{3}$ into Formate with Protein-based Biomass over $\mathrm{Pd} / \gamma-\mathrm{Al}_{2} \mathrm{O}_{3}$ Nanocatalysts
}

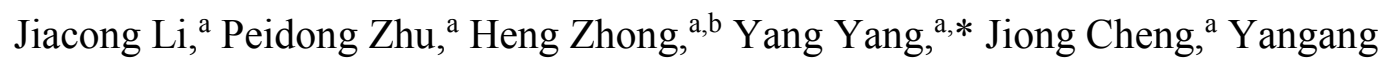
Wang ${ }^{\mathrm{d}}$ and Fangming Jin $\mathrm{Jin}^{\mathrm{a}, \mathrm{c}, *}$

${ }^{a}$ School of Environmental Science and Engineering, State Key Lab of Metal Matrix Composites, Shanghai Jiao Tong University, 800 Dongchuan Road, Shanghai 200240, China.

${ }^{b}$ Center of Hydrogen Science, Shanghai Jiao Tong University, 800 Dongchuan Road, Shanghai 200240, China.

${ }^{c}$ Shanghai Institute of Pollution Control and Ecological Security, 800 Dongchuan RD, Shanghai 200240, China.

${ }^{d}$ College of Biological Chemical Science and Engineering, Jiaxing University, 56

South Yuexiu Road, Jiaxing 314001, China.

Corresponding Authors:

* Fangming Jin: +86-21-54742283, fmjin@sjtu.edu.cn

* Yang Yang: +86-21-54745410, yangyang0120@sjtu.edu.cn

\section{Table of Contents}

Number of pages: 17

Number of figures: 7

Number of tables: 3

Number of equations: 1 


\section{Materials}

Glycine (99\%), L-alanine (99\%), L-phenylalanine (99\%), L-proline (98\%), Ltyrosine (99\%), L-glutamic acid (99\%), L-lysine (98.5\%), and bovine serum albumin (BSA, N>13.5\%) were supplied from Saan Chemical Technology (Shanghai) Co., Ltd.. Spirulina and chlorella were purchased from Yunnan Natural Biotech Co., Ltd. and Shandong Binzhou TianJia Biotechnology Co., Ltd., respectively. $\mathrm{CuCl}_{2} \cdot 2 \mathrm{H}_{2} \mathrm{O}(99 \%)$, $\mathrm{CoCl}_{2} \cdot 6 \mathrm{H}_{2} \mathrm{O}(99 \%), \mathrm{NiCl}_{2} \cdot 6 \mathrm{H}_{2} \mathrm{O}(99 \%)$ were bought from Shanghai Aladdin Biochemical Technology Co., Ltd., and $\mathrm{K}_{2} \mathrm{PdCl}_{4}(\mathrm{Pd} \geq 32.6 \%), \mathrm{PtCl}_{4}(\mathrm{Pt} \geq 57 \%)$, $\mathrm{RuCl}_{3} \cdot \mathrm{H}_{2} \mathrm{O}(98 \%)$ were obtained from Shanghai Macklin Biochemical Technology Co., Ltd.. $\gamma-\mathrm{Al}_{2} \mathrm{O}_{3}$ (99.99\%), $\mathrm{ZrO}_{2}$ (99.99\%), $\mathrm{CeO}_{2}$ (99.95\%), $\mathrm{ZnO}(99.99 \%)$, and $\mathrm{SiO}_{2}$ (99.99\%) were purchased from Shanghai Aladdin Biochemical Technology Co., Ltd., and active carbon $(>98 \%)$ was bought from Shanghai Macklin Biochemical Technology Co., Ltd.. $\mathrm{NaHCO}_{3}(>99.8 \%)$ was purchased from Shanghai Aladdin Biochemical Technology Co., Ltd.. Ar (99.9995\%, 50L) was procured from Air Liquide (Shanghai) Compressed Gas Co., Ltd., and $\mathrm{N}_{2}(99.99 \%, 8 \mathrm{~L}), \mathrm{CO}_{2}(99.99 \%$, 8L), $\mathrm{CH}_{4}(99.99 \%, 8 \mathrm{~L})$ were procured from Shanghai Weichuang Standard Gas Analysis Technology Co., Ltd.. All chemical reagents were used as received without further treatment and aqueous solutions were prepared using deionized water with a resistivity of $18.25 \mathrm{M} \Omega \cdot \mathrm{cm}^{-1}$. 


\section{Detailed information of analysis}

Analysis of catalysts. The practical mass loading of the catalyst and N-containing ions $\left(\mathrm{NH}_{4}^{+}, \mathrm{NO}_{2}^{-}, \mathrm{NO}_{3}^{-}\right)$were measured by ICP-AES equipped with the model of iCAP6300 and ion chromatography. All of the catalysts were dissolved by aqua regia at $100{ }^{\circ} \mathrm{C}$ for $12 \mathrm{~h}$ before the analysis and all of the aqueous samples were directly measured without pretreatments. The surface area and pore volume of the catalysts were studied through nitrogen adsorption/desorption experiments by an Autosorb-IQ3 apparatus. $100 \mathrm{mg}$ samples were first dried at $200{ }^{\circ} \mathrm{C}$ for $24 \mathrm{~h}$ and then liquid nitrogen was adsorbed on the surface of the catalysts to form single layer at $77 \mathrm{~K}$. After nitrogen adsorption/desorption, the specific area and porosity of the catalysts were calculated by a BET model. The crystalline phase of the catalysts were determined by XRD using a Rigaku D/ max $2550 \mathrm{~V}$ with $\mathrm{Cu}-\mathrm{K} \alpha$ radiation $(\lambda=1.5406 \AA)$ at room temperature. The X-ray tube was operated at $40 \mathrm{kV}$ and $30 \mathrm{~mA}$, and the X-ray diagram was scanned in steps of $2^{\circ}$ and an accumulation time of $0.6 \mathrm{~s}$ per step from 10 to $80^{\circ}$. XPS analysis was performed using a Thermo ESCALAB 250Xi with monochromatic Al-K $\alpha$ radiation by the Thermo Fisher Scientific to investigate the structure and valence states of Pd on the surface of catalyst. The nanostructure and Pd particles distribution on the catalysts were investigated by transmission electron microscopy (TEM; JEM-2100F) with an accelerating voltage of $200 \mathrm{kV}$. To analyze the adsorbed species on catalysts surface before and after the reaction, Fourier-transform infrared spectroscopy (FT-IR) analysis was performed with Thermo Fisher, iS10. 
Analysis of reaction samples. Liquid product $\mathrm{HCOONa}$ was quantified by an Agilent 1200 high-performance liquid chromatography (HPLC) equipped with two KC-811 columns (SHODEX) and a UV/Vis absorbance detector adjusted at $210 \mathrm{~nm} .2$ mmol/ $\mathrm{L} \mathrm{HClO}_{4}$ was used as the mobile phase with constant $1 \mathrm{~mL} / \mathrm{min}$ flow rate. Meanwhile, to determine other products, liquid samples were analyzed by an Agilent 7890A gas chromatography-mass spectrometry (GC-MS), which was equipped with an HP-INNOWAX column $(30 \mathrm{~m} \times 0.25 \mathrm{~mm} \times 0.25 \mu \mathrm{m})$ and tested by a $5975 \mathrm{C}$ inert MSD with Triple-Axis detector. During the analysis, temperatures of inlet and detector were kept at $220^{\circ} \mathrm{C}$ and $240^{\circ} \mathrm{C}$, respectively, and the temperature program of the oven was from $40{ }^{\circ} \mathrm{C}$ (maintaining for $1 \mathrm{~min}$ ) to $230^{\circ} \mathrm{C}$ at a ramp of $7{ }^{\circ} \mathrm{C} / \mathrm{min}$. Gaseous samples were analyzed by an Agilent 7890A gas chromatography-thermal conductivity detector (GC-TCD) equipped with a TDX-01 packed column. He was applied as the carrier gas with a $65 \mathrm{~mL} / \mathrm{min}$ flow rate to detect $\mathrm{N}_{2}$ and $\mathrm{CO}_{2}$. $\mathrm{N}_{2}$ was applied as the carrier gas with a $65 \mathrm{~mL} / \mathrm{min}$ flow rate for detecting $\mathrm{CH}_{4}$ and $\mathrm{H}_{2} \cdot{ }^{2} \mathrm{H}-\mathrm{NMR}$ and ${ }^{13} \mathrm{C}-\mathrm{NMR}$ analysis were performed on a Bruker ADVANCE III spectrometer at resonance frequency of 600 $\mathrm{MHz}$ to study the function of water and distribution of $\mathrm{NaHCO}_{3}$ on formate production. Dimethyl sulfoxide (DMSO) and $\mathrm{CH}_{3}{ }^{13} \underline{\mathrm{COOH}}$ were added respectively as the internal standards for quantifying the D-labelled and ${ }^{13} \mathrm{C}$-labelled formate concentrations. 
Computational details. Vienna ab initio simulation package (a version of 5.4.4) were applied for all DFT calculations. ${ }^{\text {S1-S2 }}$ The electron-exchange and -correlation energies were treated within the generalized gradient approximation in the Perdew-BurkeErnzerhof functional (GGA-PBE). ${ }^{\mathrm{S} 3}$ The core and valence electrons were represented by the projector augmented wave (PAW) potential, ${ }^{\mathrm{S} 4}$ and the plane wave basis set with a cut off energy of $400 \mathrm{eV}$ was used. The $\mathrm{p}(6 \times 6)$ slab models of bulk Pd used here are separated by a vacuum of $15 \AA$ for the accurate surface energies calculations.

The Momkhorst-Pack sampling method of $1 \times 1 \times 1$ was used to generate $\mathrm{k}$ meshes for integration of the first Brillouin zone for Pd (111) surfaces. For the surface calculations, the top two layers were relaxed and the bottom four layers were frozen. The unit cells are optimized until forces on the atoms are less than $0.05 \mathrm{eV} / \AA$, and the total energy change between two successive steps is less than $1 \times 10^{-4} \mathrm{eV}$. The transition states were estimated using the climbing image nudged elastic band method (CINEB), ${ }^{55}$ which was further confirmed by the normal mode frequency analysis, showing only one imaginary mode. 


\section{Supplementary Figures}

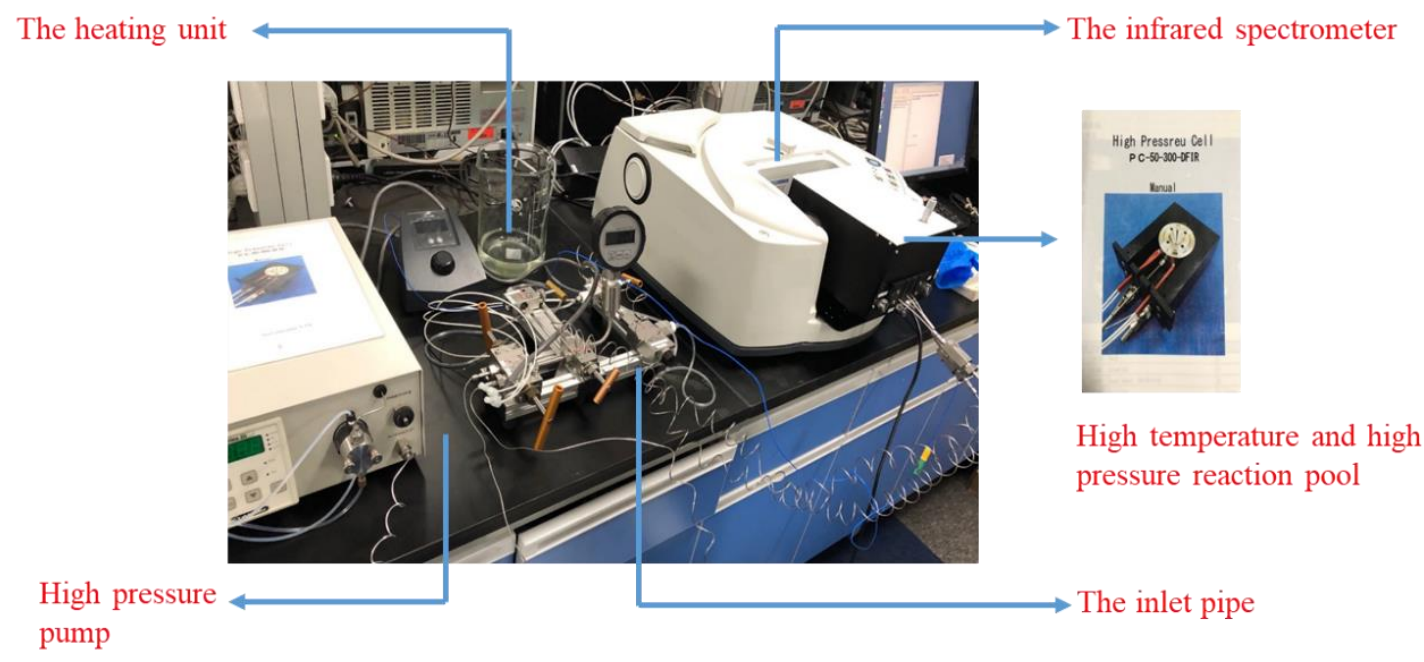

Figure S1. Schematic diagram of HTHP in-situ FT-IR. 


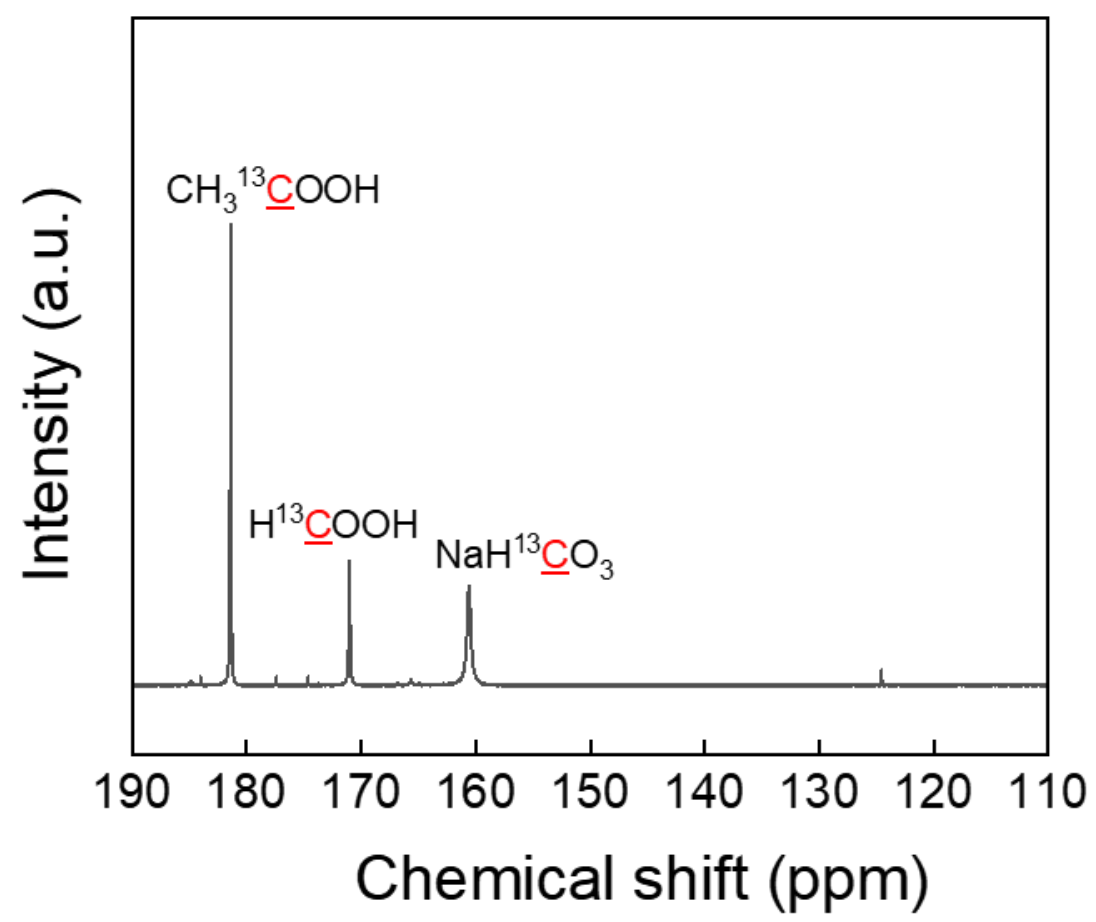

Figure S2. ${ }^{13} \mathrm{C}-\mathrm{NMR}$ spectrum of liquid sample after L-alanine reaction with $\mathrm{NaH}^{13} \mathrm{CO}_{3}$ (Reaction conditions: $0.75 \mathrm{~mol} \cdot \mathrm{L}^{-1} \mathrm{~L}$-alanine, $1.2 \mathrm{~mol} \cdot \mathrm{L}^{-1} \mathrm{NaH}^{13} \mathrm{CO}_{3}, 300 \square$, $50 \%$ water filling, $2 \mathrm{~h}$. $\mathrm{CH}_{3}{ }^{13} \mathrm{COOH}$ was added as internal standard to calculate ${ }^{13} \mathrm{C}$ labelled formate concentration) 


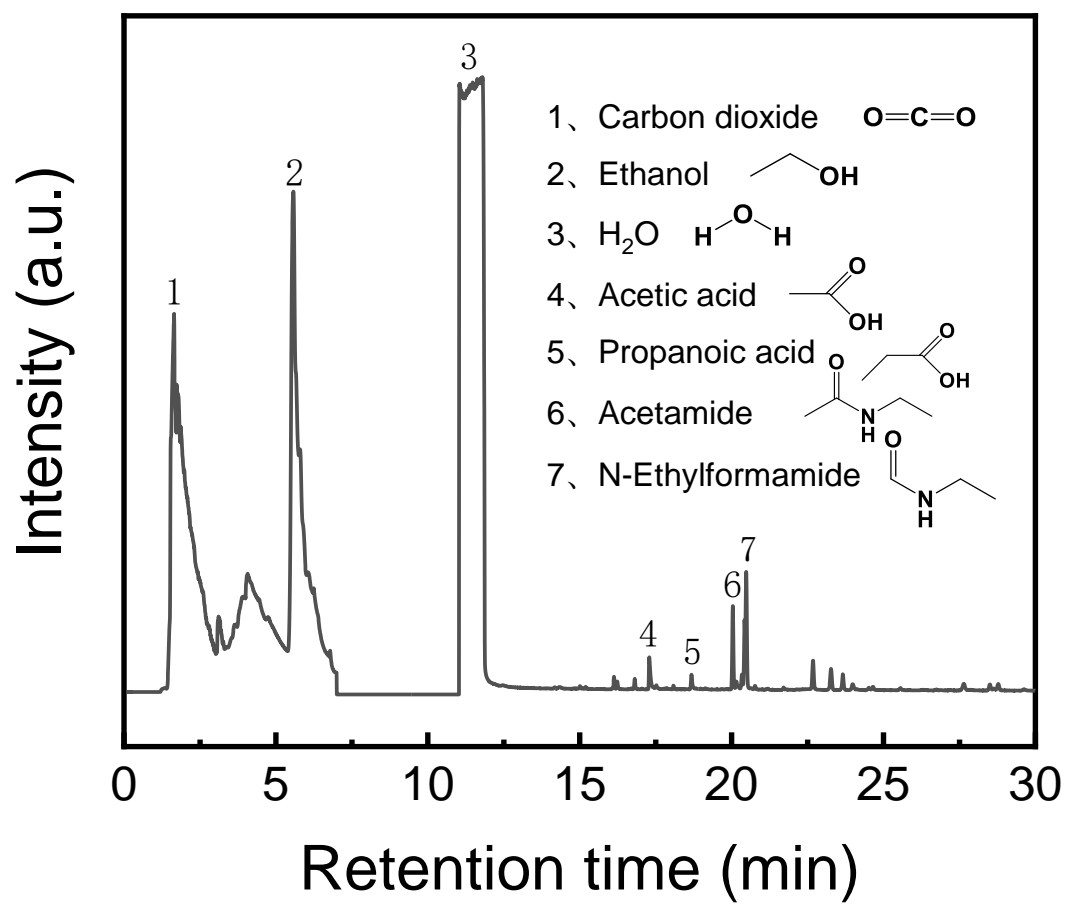

Figure S3. GC-MS analysis of liquid samples after $\mathrm{NaHCO}_{3}$ reaction with $\mathrm{L}$-alanine $\left(0.8 \mathrm{~mol} \cdot \mathrm{L}^{-1} \mathrm{~L}\right.$-alanine, $0.8 \mathrm{~mol} \cdot \mathrm{L}^{-1} \mathrm{NaHCO}_{3}, 0.08 \mathrm{~g} 5 \% \mathrm{Pd} / \gamma-\mathrm{Al}_{2} \mathrm{O}_{3}, 325{ }^{\circ} \mathrm{C}, 2 \mathrm{~h}, 50 \%$ water filling). 

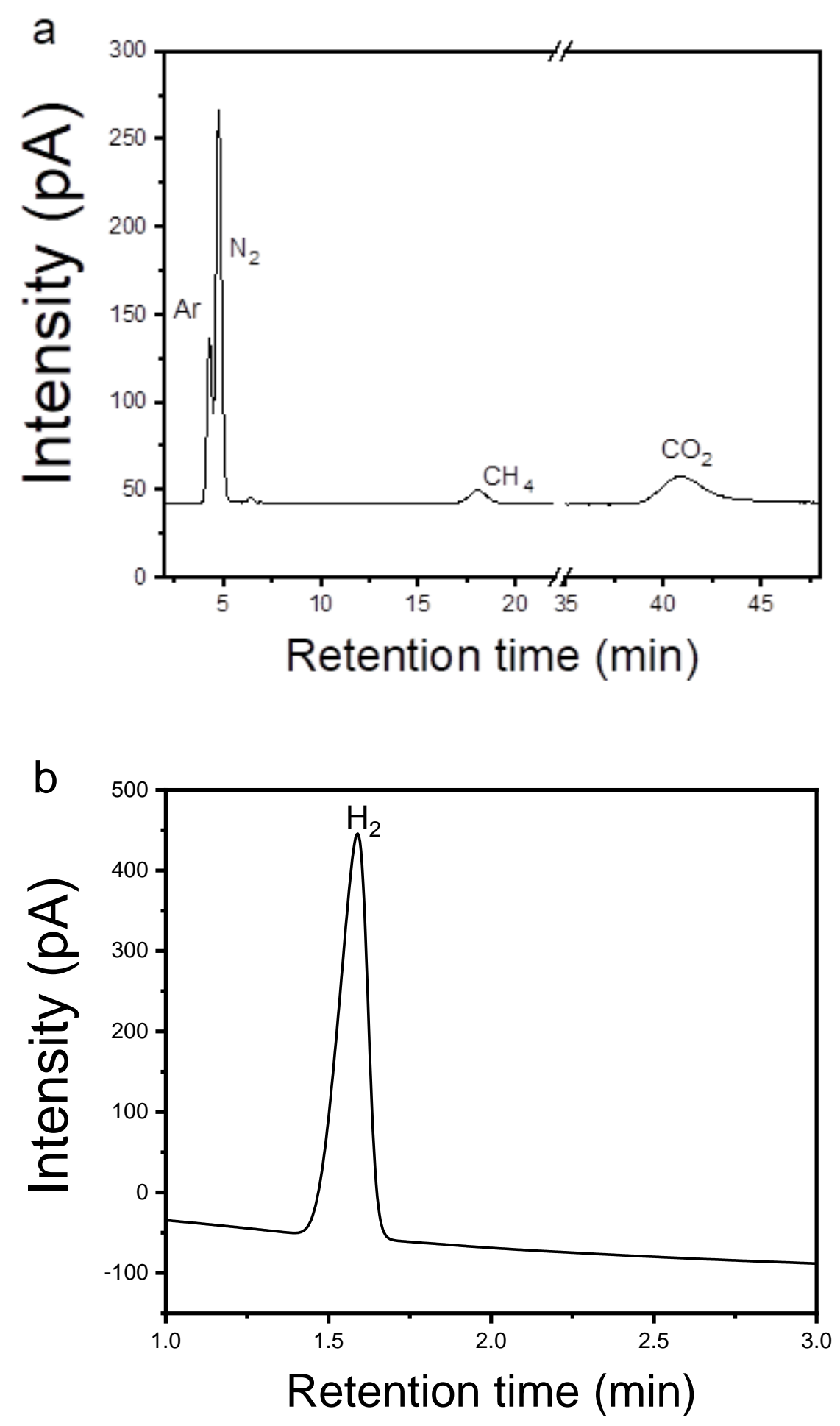

Figure S4. TCD spectra of gaseous samples after $\mathrm{NaHCO}_{3}$ reaction with $\mathrm{L}$-alanine $(0.8$ $\mathrm{mol} \cdot \mathrm{L}^{-1} \mathrm{~L}$-alanine, $0.8 \mathrm{~mol} \cdot \mathrm{L}^{-1} \mathrm{NaHCO}_{3}, 0.08 \mathrm{~g} 5 \% \mathrm{Pd} / \gamma-\mathrm{Al}_{2} \mathrm{O}_{3}, 325^{\circ} \mathrm{C}, 2 \mathrm{~h}, 50 \%$ water filling. For the analysis of $\mathrm{N}_{2}$ and $\mathrm{CO}_{2}, \mathrm{He}$ was used as the carrier gas (a), and for the analysis of $\mathrm{H}_{2}, \mathrm{~N}_{2}$ was used as the carrier gas (b)). 


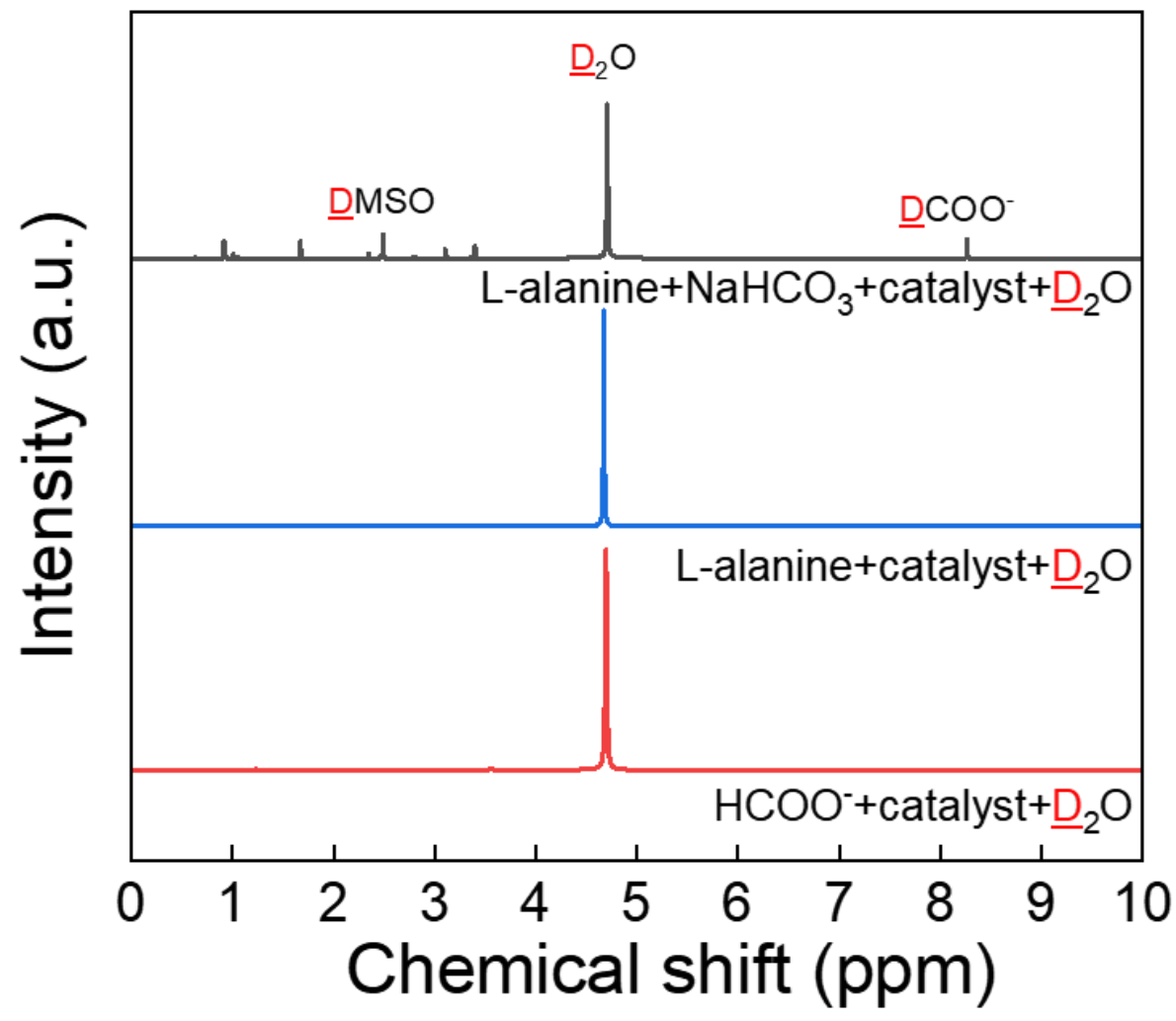

Figure S5. ${ }^{2} \mathrm{H}-\mathrm{NMR}$ spectra of liquid sample after L-alanine reaction with $\mathrm{NaHCO}_{3}$ in $\mathrm{D}_{2} \mathrm{O}$ (Reaction conditions: $0.8 \mathrm{~mol} \cdot \mathrm{L}^{-1} \mathrm{~L}$-alanine, $0.8 \mathrm{~mol} \cdot \mathrm{L}^{-1} \mathrm{NaHCO}_{3}, 0.08 \mathrm{~g} 5 \% \mathrm{Pd} / \gamma$ $\mathrm{Al}_{2} \mathrm{O}_{3}, 300 \square, 50 \%$ water filling, $2 \mathrm{~h}$. Dimethyl sulfoxide (DMSO) was added as internal standard to calculate D-labelled formate concentration). 


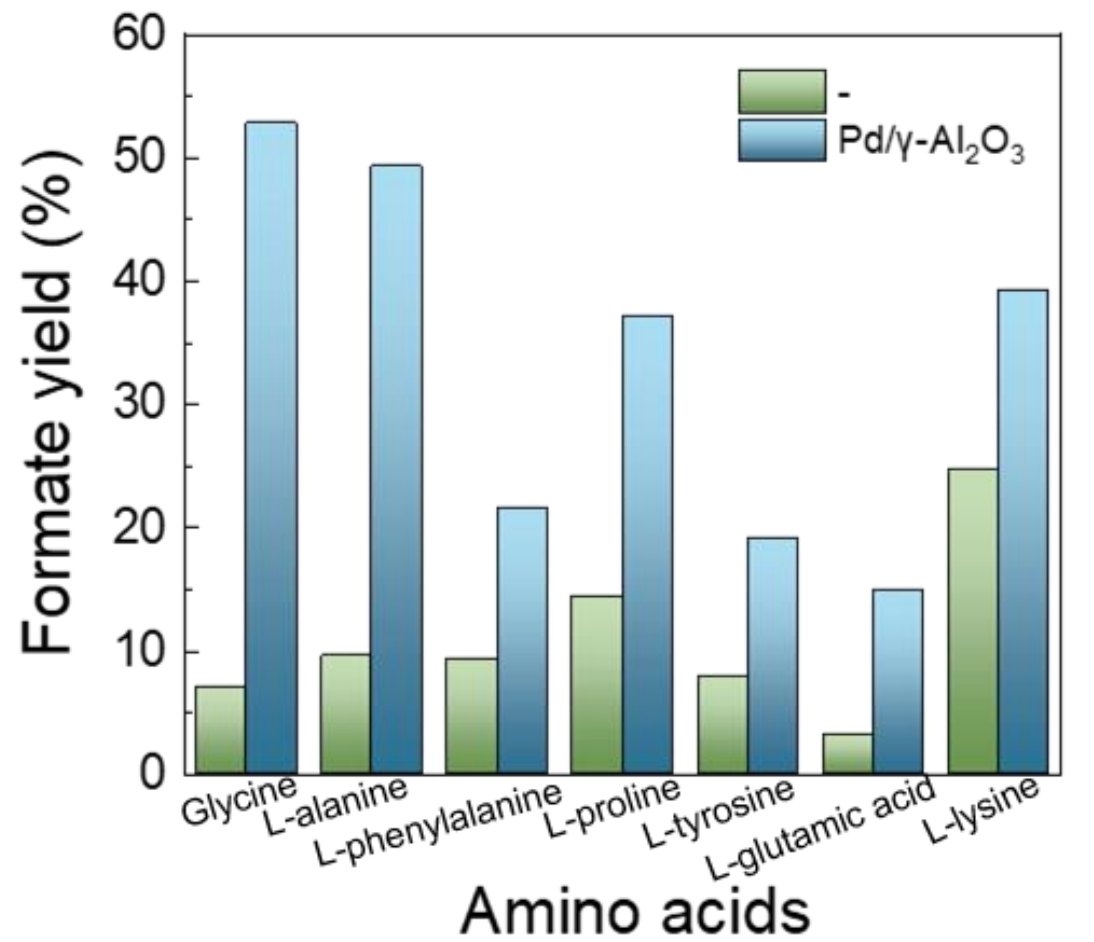

Figure S6. Formate yields of $\mathrm{NaHCO}_{3}$ reduction by different amino acids with or without $5 \% \mathrm{Pd} / \gamma-\mathrm{Al}_{2} \mathrm{O}_{3}$ (Reaction conditions: $0.8 \mathrm{~mol} \cdot \mathrm{L}^{-1}$ amino acid, $0.8 \mathrm{~mol} \cdot \mathrm{L}^{-1}$

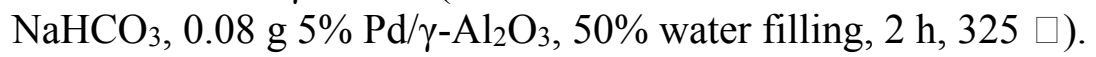




\section{Methylamine (Glycine)}

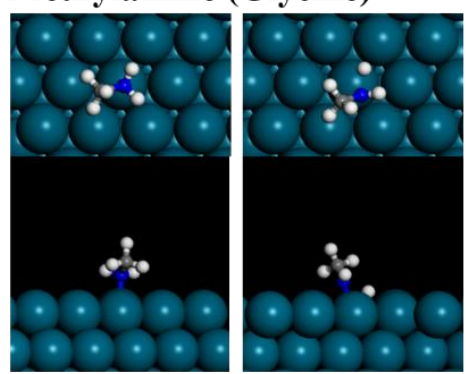

Benzylamine (L-phenylalanine)
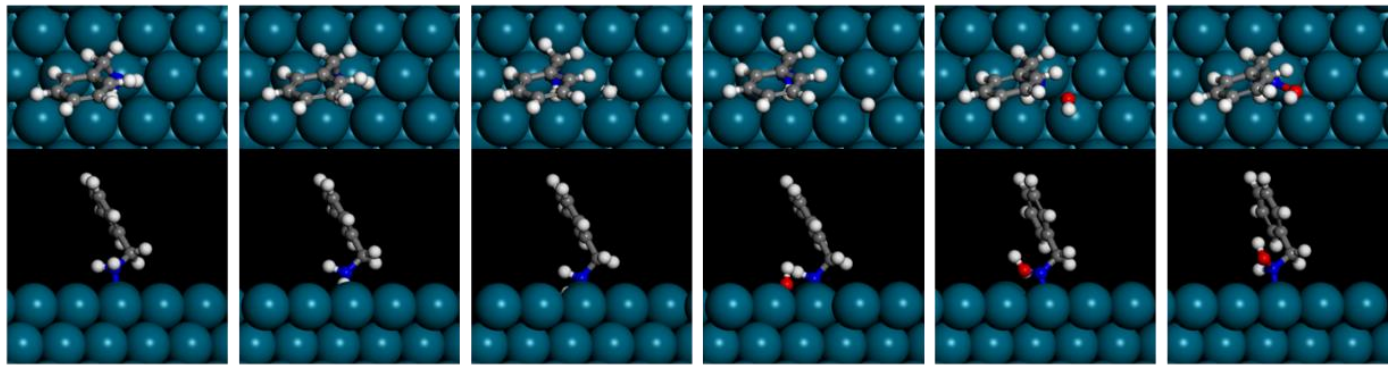

Diaminopentane (L-lysine)

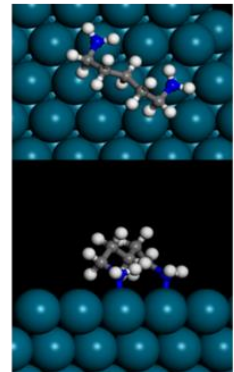

Initial

State 1

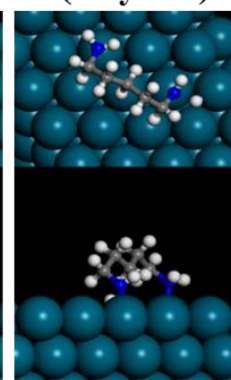

Transition

State 1

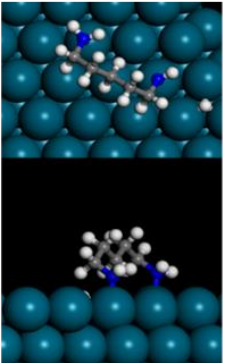

Final

State 1

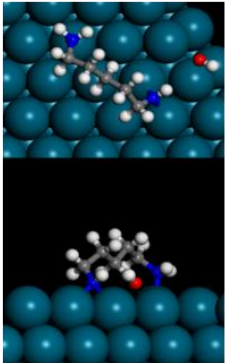

Initial

State 2
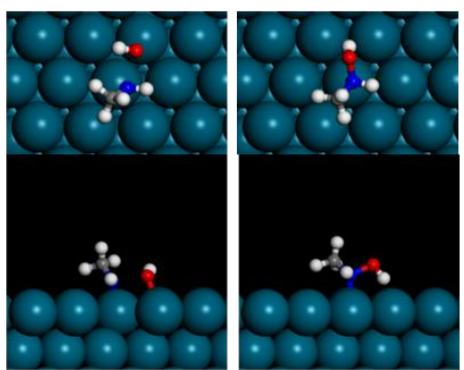

Figure S7. The structures for the stable molecular mode state for the two-step dehydrogenation reaction of the different amino acids on $\operatorname{Pd}(111)$. 


\section{Supplementary Tables}

Table S1. Zeta potential of different Pd-based catalysts. ${ }^{a}$

\begin{tabular}{ccc}
\hline Entry & Catalysts & Zeta potential $/ \mathrm{mV}$ \\
\hline 1 & $\mathrm{Pd} / \mathrm{SiO}_{2}$ & 30.04 \\
2 & $\mathrm{Pd} / \mathrm{ZrO}_{2}$ & 33.25 \\
3 & $\mathrm{Pd} / \mathrm{CeO}_{2}$ & -38.31 \\
4 & $\mathrm{Pd} / \gamma-\mathrm{Al}_{2} \mathrm{O}_{3}$ & 42.36 \\
5 & $\mathrm{Pd} / \mathrm{ZnO}$ & -9.90 \\
6 & $\mathrm{Pd} / \mathrm{C}$ & 26.23
\end{tabular}

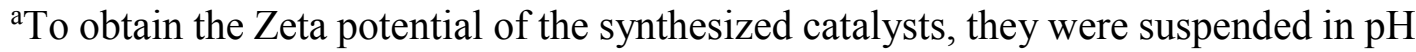
$=8.3 \mathrm{NaOH}$ solution and dispersed by ultrasonic for $1 \mathrm{~h}$. After that Zeta potential was detected by Zeta potentiometer. 
Table S2. The concentrations of formate and acetate after L-alanine reaction with/without $\mathrm{NaHCO}_{3}{ }^{\text {a }}$

\begin{tabular}{|c|c|c|}
\hline Reactants & $\begin{array}{l}\text { Formate } \\
\mathrm{mmol} \cdot \mathrm{L}^{-1}\end{array}$ & $\begin{array}{c}\text { Acetate } \\
\mathrm{mmol} \cdot \mathrm{L}^{-1}\end{array}$ \\
\hline $\mathrm{L}$-alanine $+\mathrm{NaOH}^{\mathrm{b}}+\mathrm{Pd} / \gamma-\mathrm{Al}_{2} \mathrm{O}_{3}$ & 10.3 & 10.2 \\
\hline $\begin{array}{c}\text { L-alanine }+\mathrm{NaHCO}_{3}+\mathrm{Pd} / \gamma- \\
\mathrm{Al}_{2} \mathrm{O}_{3}\end{array}$ & 388.8 & 8.7 \\
\hline \multicolumn{3}{|c|}{ 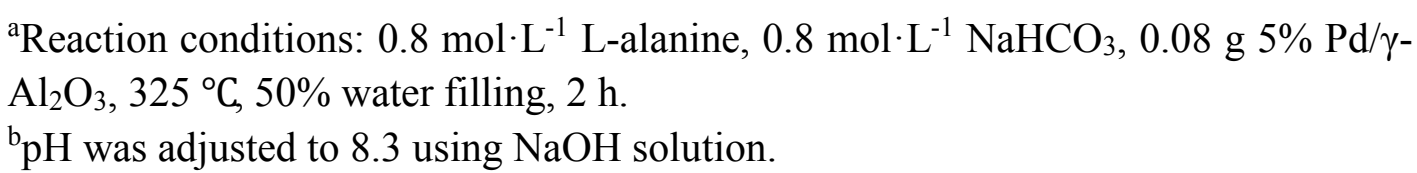 } \\
\hline
\end{tabular}


Table S3. The activation energy of transition state on $\operatorname{Pd}(111)$.

\begin{tabular}{cccc}
\hline$\Delta \mathrm{E}(\mathrm{eV})$ & Methylamine & Benzylamine & Diaminopentane \\
\hline Transition State 1 & 1.69 & 1.69 & 1.19 \\
Transition State 2 & 1.49 & 1.91 & 2.17 \\
\hline
\end{tabular}




\section{Supplementary Equation}

Equation S1. The chemical equation of $\mathrm{NaHCO}_{3}$ with ethanol.

$$
\mathrm{CH}_{3} \mathrm{CH}_{2} \mathrm{OH}+2 \mathrm{NaHCO}_{3} \rightarrow \mathrm{CH}_{3} \mathrm{COOH}+2 \mathrm{HCOONa}
$$




\section{Reference}

(S1) Kresse, G.; Furthmüller, J. Efficient iterative schemes for ab initio total-energy calculations using a plane-wave basis set. Phys. Rev. B 1996, 54 (16), 11169-11186. https://doi.org/10.1103/PhysRevB.54.11169

(S2) Kresse, G.; Joubert, D. From ultrasoft pseudopotentials to the projector augmented-wave method. Phys. Rev. B 1999, 59 (3), 1758-1775. https://doi.org/10.1103/PhysRevB.59.1758

(S3) Perdew, J. P.; Burke, K.; Ernzerhof, M., Generalized gradient approximation made simple. Phys. Rev. Lett. 1996, 77 (18), 3865-3868. https://doi.org/10.1103/PhysRevLett.77.3865

(S4) Blöchl, P. E. Projector augmented-wave method. Phys. Rev. B 1994, 50 (24), 17953-17979. https://doi.org/10.1103/PhysRevB.50.17953

(S5) Henkelman, G.; Uberuaga, B. P.; Jonsson, H., A climbing image nudged elastic band method for finding saddle points and minimum energy paths. J. Chem. Phys. 2000, 113 (22), 9901-9904. https://doi.org/10.1063/1.1329672 